\title{
Clinically relevant quality measures for risk factor control in primary care: a retrospective cohort study
}

Stefan Weiler ${ }^{1}$, Armin Gemperli ${ }^{2,3,4}$, Tinh-Hai Collet ${ }^{5,6}$, Douglas C Bauer ${ }^{7,8}$, Lukas Zimmerli, ${ }^{9,10}$, Jacques Cornuz ${ }^{5}$, Edouard Battegay ${ }^{9,10}$, Jean-Michel Gaspoz ${ }^{11}$, Eve A Kerr ${ }^{12}$, Drahomir Aujesky ${ }^{1}$ and Nicolas Rodondi ${ }^{*}$

\begin{abstract}
Background: Assessment of the proportion of patients with well controlled cardiovascular risk factors underestimates the proportion of patients receiving high quality of care. Evaluating whether physicians respond appropriately to poor risk factor control gives a different picture of quality of care. We assessed physician response to control cardiovascular risk factors, as well as markers of potential overtreatment in Switzerland, a country with universal healthcare coverage but without systematic quality monitoring, annual report cards on quality of care or financial incentives to improve quality.
\end{abstract}

Methods: We performed a retrospective cohort study of 1002 randomly selected patients aged 50-80 years from four university primary care settings in Switzerland. For hypertension, dyslipidemia and diabetes mellitus, we first measured proportions in control, then assessed therapy modifications among those in poor control. "Appropriate clinical action" was defined as a therapy modification or return to control without therapy modification within 12 months among patients with baseline poor control. Potential overtreatment of these conditions was defined as intensive treatment among low-risk patients with optimal target values.

Results: $20 \%$ of patients with hypertension, $41 \%$ with dyslipidemia and $36 \%$ with diabetes mellitus were in control at baseline. When appropriate clinical action in response to poor control was integrated into measuring quality of care, 52 to $55 \%$ had appropriate quality of care. Over 12 months, therapy of $61 \%$ of patients with baseline poor control was modified for hypertension, 33\% for dyslipidemia, and $85 \%$ for diabetes mellitus. Increases in number of drug classes (28-51\%) and in drug doses (10-61\%) were the most common therapy modifications. Patients with target organ damage and higher baseline values were more likely to have appropriate clinical action. We found low rates of potential overtreatment with 2\% for hypertension, 3\% for diabetes mellitus and 3-6\% for dyslipidemia.

Conclusions: In primary care, evaluating whether physicians respond appropriately to poor risk factor control, in addition to assessing proportions in control, provide a broader view of the quality of care than relying solely on measures of proportions in control. Such measures could be more clinically relevant and acceptable to physicians than simply reporting levels of control.

Keywords: Clinical inertia, Blood pressure, Quality of care, Pharmacological intervention, Hypertension, Dyslipidemia, Diabetes mellitus, Cohort study

\footnotetext{
* Correspondence: nicolas.rodondi@insel.ch

'Department of General Internal Medicine, University of Bern, Bern, Switzerland

Full list of author information is available at the end of the article
} 


\section{Background}

Although a broad armamentarium of pharmacotherapeutic interventions and recommendations are available, cardiovascular risk factors are often suboptimally controlled. Clinical inertia in the form of insufficient treatment intensification in the face of poor disease control has been suggested to be a major cause of failure to respond to abnormal measurements [1,2]. While quality of care measures should ideally reflect whether physicians and systems deliver appropriate clinical action, most current measures focus on achievement of a target rather than changes in treatment [3].

We have previously shown the feasibility of measuring physician response to poor risk factor control in the US using electronic treatment records as an additional "tightly linked" clinical action measure of quality [4,5]. Provider responses to poorly controlled risk factor levels such as intensification of pharmacotherapy are tightly linked clinical action measures, which are clinically relevant indicators for quality of care directly linked to improved patient outcomes, further improving quality assessment and reducing risks of overtreatment $[3,4,6]$. The primary goal of new action measures is the improvement of quality of care. Focusing on accountability measures might corrupt the process of monitoring quality of care [7].

Recently, new measures have also been developed for potential overtreatment of cardiovascular risk factors, such as hypertension and diabetes mellitus $[3,8]$. However, limited data exist about physician response to poor risk factor control and markers of overtreatment in settings without systematic quality monitoring. In Switzerland, systematic quality monitoring and annual report cards on quality of care [9], and financial incentives to improve quality, are not implemented. Among other differences from the US, all patients have universal healthcare coverage in Switzerland.

In the present study, we assessed physician response to control of hypertension, dyslipidemia, and diabetes mellitus, as well as markers of potential overtreatment, among a random sample of 1002 patients aged 50-80 years followed for two years in four Swiss University primary care settings.

\section{Methods}

\section{Study participants}

We abstracted medical charts from 1002 randomly selected patients from Swiss university primary care settings in Basel, Geneva, Lausanne and Zürich to establish a retrospective cohort study over 2 years, as described previously in detail [10]. The Institutional Review Boards at each site approved the study. This study was approved by the Ethics Committee of Zürich, the Human Research Ethics Committee of Geneva, the Human Research Ethics Committee of Vaud, and the Ethics Committee of Basel, at the sites of Zürich, Geneva, Lausanne, and Basel, respectively. The random sample was drawn from electronic administrative data of all patients aged 50 to 80 years followed in 20052006. We limited our sample to this age group to have a high enough prevalence of cardiovascular risk factors. Patients were followed by residents in general internal medicine at the end of their postgraduate training who were supervised by university attendings, or were seen directly by university attendings (10\%). Patients who were followed for less than one year, in a specialized clinic only or who had no outpatient visit to a primary care physician were excluded. Nine medical students were centrally trained at one site (Lausanne) for data abstraction from medical charts in each Swiss university primary care setting, and then entered data using EpiData software (version 3.1, EpiData Association, Denmark). We used the same criteria for the identification of patients with hypertension, dyslipidemia, diabetes mellitus as previously published (Additional file 1: Table S1) [5].

\section{Diagnostic criteria for "Appropriate Clinical Action"}

Among patients with poorly controlled hypertension, dyslipidemia, or diabetes mellitus during the study period, we assessed any therapy modification response to one or more poorly controlled conditions [5]. Patients with near control of risk factors were not analyzed for therapy modifications because of the appropriateness of lifestyle modifications for near control of these conditions. Patients with diabetes already treated with insulin therapy were not included into the analysis of therapy modifications, because day-to-day adjustments in insulin dosage could not be reliably identified.

We defined pharmacotherapeutic intervention as an increase in the number of different drug classes, an increase in the dosage of one or more drugs, or a switch to another drug class. We defined "appropriate clinical action" as any of these pharmacotherapeutic interventions or return to control without therapy modification within 12 months as physicians may sometimes opt for non-pharmacological recommendations [5]. Responses were also examined within six months. Other possibilities were considered "inappropriate clinical action" as no return to control, return to "near control", or no further measurements without any pharmacotherapeutic intervention within 12 months. In terms of quality of care, we compared the differences between simply measuring proportions of patients with controlled risk factors (markers in control) and adding appropriate clinical action for those with poor risk factor control (action measure).

Drugs were grouped into drug classes, with seven antihypertensive classes (thiazides diuretics, other diuretics, betablockers, calcium-channel blockers, angiotensin-converting enzyme inhibitors, angiotensin-receptor blockers, other antihypertensives), five lipid-lowering classes (statins, fibric acid derivatives, niacin, bile acid resins, other 
lipid-lowering agents), and five antidiabetic classes (insulin, sulfonylureas, metformin, thiazolidinediones, other diabetes-related agents). Daily dosages were recorded except for insulin whose day-to-day adjustments could not be reliably identified in this retrospective review of medical charts.

\section{Comorbidities}

We analyzed the associations between various patient factors, such as co-occurrence of several conditions or target organ disease and "appropriate clinical action" for poorly controlled conditions. Target organ disease is based on the definitions of the Joint National Committee 7th report guidelines [11]: any previous diagnosis of hypertensive heart disease, congestive heart failure, cerebrovascular or peripheral arterial disease, and nephropathy. Based on a previous published study [12], another predictor variable was the number of comorbidities. Categories of cardiovascular risk included the history of coronary artery disease (CAD), other target organ disease or no history of either condition. Previous CAD was defined as any diagnosis of myocardial infarction, angina pectoris, atherosclerotic heart disease or coronary revascularization [5].

\section{Markers of potential overtreatment}

Recently, criteria for potential overtreatment of hypertension among patients with diabetes mellitus have been developed [3]. Based on this study and on current guidelines at the time of the patient care $[11,13]$, we defined potential overtreatment of hypertension among diabetic patients if both low systolic $(<130 \mathrm{mmHg})$ and low diastolic $(<65 \mathrm{mmHg})$ values, and receiving three or more antihypertensive drugs applied to diabetics and to the overall sample. We defined potential overtreatment of dyslipidemia as having low LDL cholesterol $(<2.6 \mathrm{mmol} /$ $\mathrm{L}$ or $<100 \mathrm{mg} / \mathrm{dL}$ ) and a high daily dose of statin (atorvastatin $\geq 40 \mathrm{mg}$, rosuvastatin $\geq 10 \mathrm{mg}$, simvastatin $\geq 40 \mathrm{mg}$ ) for individuals without a diagnosis of cardiovascular disease (primary prevention) [14]. We developed new criteria for potential overtreatment of diabetes mellitus based on the new ADA guidelines which state that less stringent glycosylated haemoglobin (HbA1c) goals are possibly appropriate for patients with limited life expectancy, extensive comorbid conditions ${ }^{13}$, and supported by a commentary by Pogach and Aron [8]. Potential overtreatment of patients with diabetes was defined as patients with a low $\mathrm{HbA} 1 \mathrm{c}<7.0 \%$, on treatment with two or more glucose-lowering agents, when the patient had multi-morbidity (defined as two or more diseases, excluding cardiovascular risk factors) $[15,16]$ or a short life expectancy (defined as a terminal illness, such as cancer). We did not have any longitudinal data on therapy intensification among patients with controlled risk factors, as these data were not collected.

\section{Statistical analysis}

For patients with poorly controlled hypertension, dyslipidemia and diabetes mellitus, we examined percentages of pharmacotherapeutic interventions or return to normal levels, as described above. We examined different factors associated with "appropriate clinical action" at six and twelve months using multivariable logistic regression. We used mixed-effects logistic regression (Stata version 12.0, Stata Corp., College Station, TX) to account for clustering by the four sites as a fixed factor and physicians as random factor [17].

\section{Results}

\section{Population characteristics and degree of control}

Baseline demographic characteristics and comorbid conditions are described in Table 1. Among the 1002 patients at baseline, 753 had hypertension (20\% in control and 52\% poorly controlled), 644 had dyslipidemia (41\% in control, $36 \%$ poorly controlled), and 293 had diabetes (36\% in control, 20\% poorly controlled) (Figure 1 ). When appropriate clinical action in response to poor control over a 12 month period was integrated into measuring quality of care, the proportion of patients receiving appropriate/high quality of care increased to $52 \%$ of patients with hypertension (391 of 753 patients), 55\% of patients with dyslipidemia (351 of 644) and 53\% of patients with diabetes mellitus (155 of 293 patients) (Figure 1). The highest number of condition-specific medications was given to patients with poorly controlled hypertension, with $30 \%$ receiving three or more anti-hypertensive drugs at baseline. More than $60 \%$ of patients with poorly controlled hypertension were on three or more medications at baseline. Patients with poorly controlled dyslipidemia received the lowest number of condition-specific drugs at baseline and $71 \%$ were untreated at baseline. One to two thirds of patients with one poorly controlled condition had also the other two conditions (Table 2).

\section{Therapy modifications during 6-month and 12-month periods}

Within six months, $49 \%$ of patients received therapy modification for poorly controlled blood pressure, $24 \%$ for poorly controlled LDL cholesterol level, and $75 \%$ for poorly controlled HbA1c (Table 3). In most patients therapy was modified by adding another drug class (19-44\%) or by increasing the dosage (7-53\%). Within a longer observation period of 12 months, patients with therapy modifications slightly increased to $61 \%$ for poorly controlled blood pressure, $33 \%$ for poorly controlled LDL-cholesterol level, and $85 \%$ for poorly controlled HbA1c. Although the number of patients with therapy modifications rose between 6 and 12 months, a majority of patients had drug modifications within the first six months. Only a small 
Table 1 Baseline characteristics of patients with poorly controlled hypertension, dyslipidemia, and diabetes mellitus

\begin{tabular}{|c|c|c|c|c|c|c|}
\hline \multirow{2}{*}{$\begin{array}{l}\text { Demographic } \\
\end{array}$} & \multicolumn{2}{|c|}{$\begin{array}{l}\text { Poorly controlled } \\
\text { Hypertension }(n=391)\end{array}$} & \multicolumn{2}{|c|}{$\begin{array}{l}\text { Poorly controlled } \\
\text { Dyslipidemia }(n=231)\end{array}$} & \multicolumn{2}{|c|}{$\begin{array}{l}\text { Poorly controlled diabetes } \\
\text { Mellitus }(n=59)\end{array}$} \\
\hline & & & & & & \\
\hline \multirow[t]{2}{*}{ Age, years Mean, (SD) } & 64.5 & (8.1) & 62.9 & $(7.7)$ & 62.8 & (8.6) \\
\hline & $\mathrm{n}$ & $\%$ & $\mathrm{n}$ & $\%$ & $\mathrm{n}$ & $\%$ \\
\hline \multicolumn{7}{|l|}{ Age } \\
\hline$<65$ years & 193 & 49 & 130 & 56 & 32 & 54 \\
\hline$\geq 65$ years & 198 & 51 & 101 & 44 & 27 & 46 \\
\hline \multicolumn{7}{|l|}{ Sex } \\
\hline Female & 159 & 41 & 99 & 43 & 22 & 37 \\
\hline
\end{tabular}

\section{Baseline medications}

Medication for each condition

0 medications
1 medications
2 medications
3 medications
$\geq 4$ medications

Medication for others of the 3 conditions

0 medications

1 medications

2 medications

3 medications

$\geq 4$ medications

All medications

0 medications

1 medications

2 medications

3 medications

$\geq 4$ medications

\section{Citizenship}

Switzerland

Europe/USA

Eastern Europe

Africa

Latin America

Asia/Middle-East

10
15
16
18
42

\section{5}

10

5

20

59

\section{Civil status}

Single

Divorced/separated

51

87

Widowed

46

Married

Occupation

Social aid

Unemployed 
Table 1 Baseline characteristics of patients with poorly controlled hypertension, dyslipidemia, and diabetes mellitus (Continued)

\begin{tabular}{lllllll}
\hline Retired & 159 & 41 & 86 & 37 & 26 & 44 \\
At home & 45 & 12 & 25 & 11 & 7 & 12 \\
Other & 2 & 1 & 0 & 0 & 1 & 2 \\
\hline
\end{tabular}

Missing data on citizenship for 2 patients with poorly controlled hypertension, on civil status for 4 patients with poorly controlled hypertension and 1 patient with poorly controlled dyslipidemia, on occupation for 7 patients with poorly controlled hypertension, for 2 with poorly controlled dyslipidemia, respectively.

number of patients (0-5\%) returned to control after 12 months without any therapy modifications.

About one third of hypertensive patients with inappropriate clinical action remained in poor control without therapy modification. In contrast, more than half of the patients receiving inappropriate clinical action for poorly controlled dyslipidemia had no further LDL-cholesterol measurement within 6 or 12 months. In patients with poorly controlled diabetes mellitus and inappropriate clinical action about $70 \%$ were already receiving one or two oral antidiabetics (77\% after six months, $67 \%$ after 12 months). In contrast, among patients with poorly controlled dyslipidemia and inappropriate clinical action about $70 \%$ were not on any single lipid-lowering medication at baseline.

\section{Multivariable analysis of factors associated with} appropriate clinical action

At 12 months, previous target organ disease and CAD were independently associated with appropriate clinical action in response to poor control of dyslipidemia (Table 4). Higher baseline levels of systolic and diastolic blood pressure and LDL cholesterol levels were associated with a higher proportion of appropriate clinical action for poorly controlled hypertension and dyslipidemia. Patient gender or age did not influence appropriate clinical action. Hypertensive patients with CAD or target organ damage were not more likely to receive appropriate clinical action in response to elevated blood pressure, than those without these conditions using multivariable analyses.

\section{Potential overtreatment of hypertension, dyslipidemia and diabetes mellitus}

Five out of 256 (2\%) diabetic patients with hypertension met the criteria for overtreatment. Overall, we found $2 \%$ of patients $(15 / 753)$ to be potentially overtreated for hypertension, 3\% (8/293) for diabetes mellitus, and 3\% for dyslipidemia $(19 / 644)$ whereas $6 \%$ of patients with diabetes had potential overtreatment for dyslipidemia (13/236).

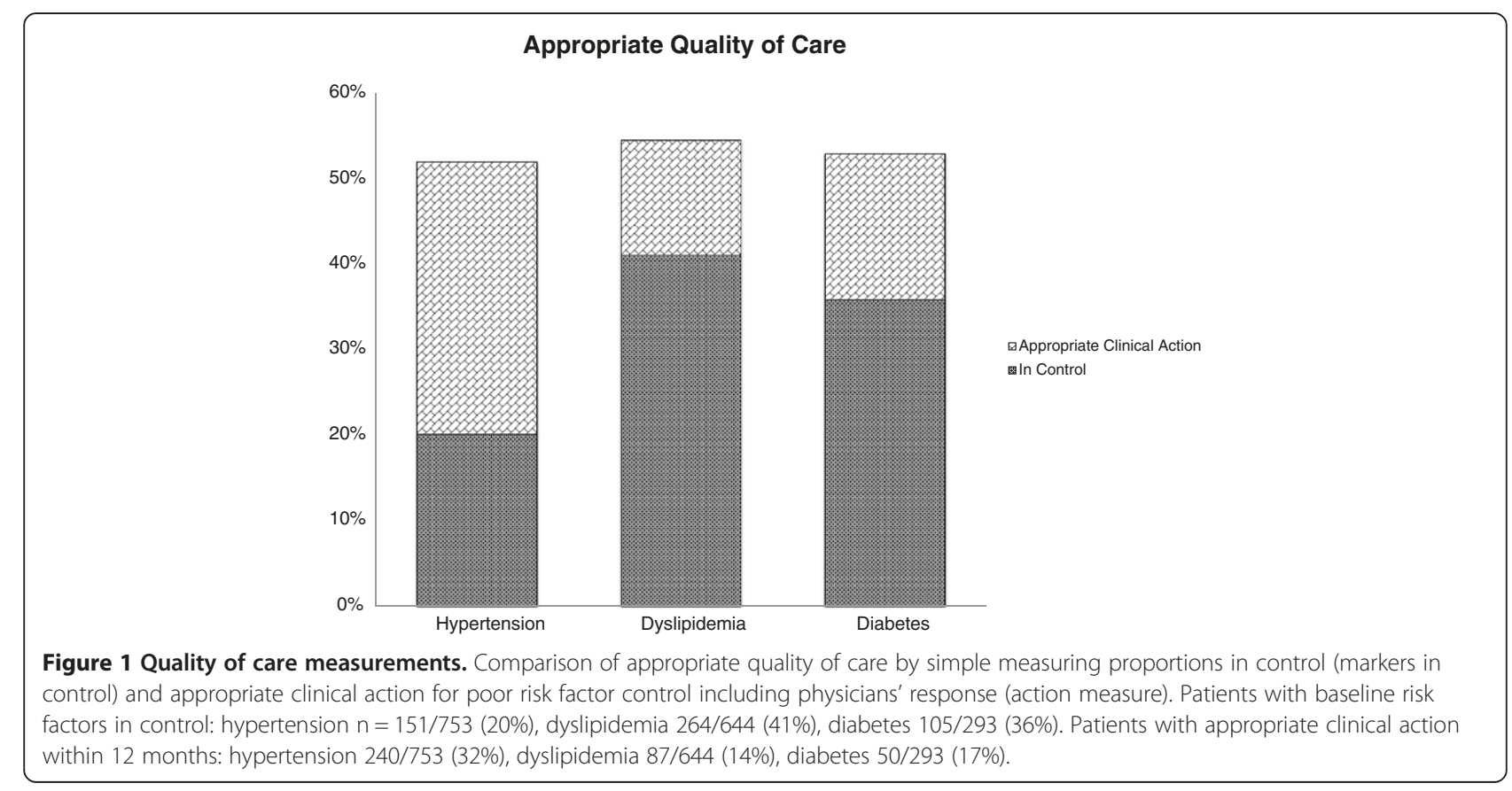


Table 2 Comorbid conditions of the patients with poorly controlled conditions

\begin{tabular}{|c|c|c|c|c|c|c|}
\hline \multicolumn{7}{|l|}{ Co-Conditions and Co-Morbidities } \\
\hline & \multicolumn{2}{|c|}{$\begin{array}{l}\text { Hypertension poor control } \\
\qquad(n=391)\end{array}$} & \multicolumn{2}{|c|}{$\begin{array}{l}\text { Dyslipidemia poor control } \\
\qquad(\mathrm{n}=231)\end{array}$} & \multicolumn{2}{|c|}{$\begin{array}{l}\text { Diabetes mellitus poor contro } \\
\qquad(n=59)\end{array}$} \\
\hline & $n$ & $\%$ & $\mathbf{n}$ & $\%$ & $\mathrm{n}$ & $\%$ \\
\hline \multicolumn{7}{|l|}{ Conditions } \\
\hline all three conditions & 141 & 36 & 60 & 26 & 41 & 69 \\
\hline + hypertension & & & 187 & 81 & 51 & 86 \\
\hline + dyslipidemia & 294 & 75 & & & 48 & 81 \\
\hline + diabetes mellitus & 169 & 43 & 70 & 30 & & \\
\hline \multicolumn{7}{|l|}{ Comorbidities } \\
\hline Cerebrovascular Disease (TIA, CVA) & 56 & 14 & 20 & 9 & 6 & 10 \\
\hline Coronary Artery Disease & 75 & 19 & 37 & 16 & 9 & 15 \\
\hline Congestive Heart Failure & 28 & 7 & 11 & 5 & 3 & 5 \\
\hline End Stage Renal Disease & 2 & 1 & 1 & 0 & 0 & 0 \\
\hline Dementia & 9 & 2 & 2 & 1 & 1 & 2 \\
\hline COPD & 50 & 13 & 28 & 12 & 10 & 17 \\
\hline Asthma & 16 & 4 & 6 & 3 & 3 & 5 \\
\hline Gastric Ulcer & 13 & 3 & 12 & 5 & 5 & 8 \\
\hline Breast Cancer & 6 & 2 & 4 & 2 & 0 & 0 \\
\hline Colorectal Cancer & 8 & 2 & 0 & 0 & 1 & 2 \\
\hline Prostate Cancer & 16 & 4 & 8 & 3 & 2 & 3 \\
\hline Depression & 68 & 17 & 46 & 20 & 12 & 20 \\
\hline \multicolumn{7}{|l|}{ Number of Comorbidities } \\
\hline Mean, (SD) & \multicolumn{2}{|c|}{$2.3(1.0)$} & \multicolumn{2}{|c|}{$1.9(1.1)$} & \multicolumn{2}{|c|}{$2.7(1.0)$} \\
\hline \multicolumn{7}{|l|}{ Distribution } \\
\hline 0 & 0 & 0 & 17 & 7 & 0 & 0 \\
\hline 1 & 87 & 22 & 72 & 31 & 3 & 5 \\
\hline 2 & 158 & 40 & 81 & 35 & 25 & 42 \\
\hline$>2$ & 146 & 37 & 61 & 26 & 31 & 53 \\
\hline
\end{tabular}

COPD chronic obstructive pulmonary disease.

\section{Discussion}

In Switzerland, a country without systematic quality monitoring, we found that measuring proportions in control without evaluating whether physicians respond appropriately to poor risk factor control largely underestimated quality of care. When appropriate clinical action in response to poor control over a 12 month period was integrated into measuring quality of care compared to the measurement of proportions of patients with controlled risk factors, proportions with appropriate quality of care increased for hypertension ( $20 \%$ vs. $52 \%$ ), for dyslipidemia ( $41 \%$ vs. $55 \%$ ), and for diabetes mellitus (36\% vs. $53 \%$ ).

Suboptimal care for poorly controlled cardiovascular risk factors was provided to $15 \%$ to $62 \%$ of patients at 12 months in our study. Failure to respond to poorly controlled measurements is a barrier to good clinical and appropriate clinical action of cardiovascular risk factors [1]. Guidelines are frequently changing. For example, recent evidence suggests that treatment with moderate dose statins is more important than achieving target values for LDL [14]. However, at baseline over $35 \%$ of patients at high risk of cardiovascular events with an LDL $>2.6 \mathrm{mmol} / \mathrm{L}$ were not treated with statins in our study. Other reasons for inappropriate clinical action might be the patients' lack of adherence to pharmacological therapy, missed appointments, missed laboratory tests or the recommendation for lifestyle modifications [18], which could not directly be identified in our data. However, return to control without any treatment, possibly due to lifestyle modifications, was counted as appropriate clinical action in our study.

To our knowledge, this is the first study in a country without systematic quality monitoring, to document appropriate physician response to poor control of cardiovascular risk factors and potential overtreatment. Systematic quality monitoring is widely used in the US and in the UK [16]. It has been shown that higher quality of care might 
Table 3 Patients with poorly controlled hypertension, dyslipidemia, or diabetes mellitus, who had subsequent therapy modifications within a 6-months or 12 months-period

\begin{tabular}{|c|c|c|c|c|c|c|c|c|c|c|c|c|}
\hline & \multicolumn{4}{|c|}{$\begin{array}{l}\text { Patients with poorly controlled } \\
\text { hypertension }\end{array}$} & \multicolumn{4}{|c|}{$\begin{array}{c}\text { Patients with poorly controlled } \\
\text { dyslipidemia }\end{array}$} & \multicolumn{4}{|c|}{$\begin{array}{l}\text { Patients with poorly controlled } \\
\text { diabetes mellitus }\end{array}$} \\
\hline & \multicolumn{2}{|c|}{6 Months } & \multicolumn{2}{|c|}{12 Months } & \multicolumn{2}{|c|}{6 Months } & \multicolumn{2}{|c|}{12 Months } & \multicolumn{2}{|c|}{6 Months } & \multicolumn{2}{|c|}{12 Months } \\
\hline & $\mathrm{n}$ & $\%$ & $\mathrm{n}$ & $\%$ & $\mathrm{n}$ & $\%$ & $\mathrm{n}$ & $\%$ & $\mathrm{n}$ & $\%$ & $\mathrm{n}$ & $\%$ \\
\hline Appropriate clinical action & 211 & 54.0 & 240 & 61.4 & 67 & 29.0 & 87 & 37.7 & 46 & 78.0 & 50 & 84.7 \\
\hline Any therapy modification & 193 & 49.4 & 238 & 60.9 & 55 & 23.8 & 77 & 33.3 & 44 & 74.6 & 50 & 84.7 \\
\hline Increase class & 121 & 30.9 & 153 & 39.1 & 43 & 18.6 & 64 & 27.7 & 26 & 44.1 & 30 & 50.8 \\
\hline Increase dose & 103 & 26.3 & 135 & 34.5 & 15 & 6.5 & 23 & 10.0 & 31 & 52.5 & 36 & 61.0 \\
\hline Switch class ${ }^{\dagger}$ & 30 & 7.7 & 49 & 12.5 & 0 & 0.0 & 2 & 0.9 & 6 & 10.2 & 10 & 16.9 \\
\hline Several modifications & 55 & 14.1 & 88 & 22.5 & 3 & 1.3 & 11 & 4.8 & 19 & 32.2 & 26 & 44.1 \\
\hline Return to control WO modification ${ }^{\ddagger}$ & 18 & 4.6 & 2 & 0.5 & 12 & 5.2 & 10 & 4.3 & 2 & 3.4 & 0 & 0.0 \\
\hline Inappropriate clinical action & 180 & 46.0 & 151 & 38.6 & 164 & 71.0 & 144 & 62.3 & 13 & 22.0 & 9 & 15.3 \\
\hline No modification, return to near control ${ }^{\ddagger}$ & 25 & 6.4 & 9 & 2.3 & 38 & 16.5 & 27 & 11.7 & 1 & 1.7 & 3 & 5.1 \\
\hline No modification, no return ${ }^{\ddagger}$ & 120 & 30.7 & 134 & 34.3 & 40 & 17.3 & 40 & 17.3 & 7 & 11.9 & 2 & 3.4 \\
\hline No measurement, no modification & 35 & 9.0 & 8 & 2.0 & 86 & 37.2 & 77 & 33.3 & 5 & 8.5 & 4 & 6.8 \\
\hline
\end{tabular}

$\mathrm{LDL}=$ low-density lipoprotein. ${ }^{\dagger} \mathrm{A}$ switch to different drug class was counted when a new class of medication for the condition was added, but the total number of drug classes remained the same. ${ }^{\ddagger}$ Categories of control with levels of control, near and poor control for hypertension, dyslipidemia and diabetes mellitus are based on N. Rodondi et al. [5]. This category includes patients without visit or measurements.

be delivered when performance measures and monitoring are established [19]. Other factors influencing physicians' prescription behaviour are likely to be similar to those in the US setting, such as adherence to the same US treatment guidelines (or slight adaptation of them) and potential industrial influence, with several industrial headquarters in Switzerland. As most physicians in our study had a fixed salary, it is unlikely that financial incentives played a significant role in our results. Previous studies on quality of care based on therapy modifications in response to cardiovascular risk factors were primarily performed in countries with quality monitoring such as the US [5,7,20-22]. In a previous study from the US, the rates of therapy modifications for poorly controlled blood pressure were comparable to our study, slightly lower for poorly controlled HbA1c, and higher for poorly controlled LDL cholesterol levels [7]. In contrast, recent studies from the US Department of Veterans Affairs showed higher levels of therapy modification and treatment, along with higher levels of potential overtreatment. In these studies, Kerr and colleagues showed that high rates of performance on measures that assessed attainment of risk factor thresholds may be associated with overtreatment $[3,14]$, while our study found high levels of therapy modification with low rates of overtreatment.

In the US studies previously reported, patients with 1 or more of the 3 conditions, those with higher baseline values of cardiovascular risk factors, target organ damage, younger age or more "routine visits" were more likely to receive appropriate clinical action for all of the three risk factors [5,23-25].
Higher rates of appropriate clinical action for poorly controlled hypertension and dyslipidemia were found among patients with higher baseline levels of blood pressure and LDL cholesterol levels, respectively. Potential overtreatment of these conditions seemed to be low for patients with already well controlled risk factors.

Results from our study show, that high rates of appropriate clinical action and low proportions of overtreatment may also be achieved in a country without systematic quality monitoring. In Switzerland all patients have universal healthcare coverage, including adults with low income who receive social aid to cover healthcare costs, regardless of their age or whether they work. Meeting clinical action measures rather than the treat-to-target approach of surrogate markers is now more and more recommended to improve appropriateness of care [3,8,14]. These measures include clinical processes that are associated with important outcomes. Simply assessing measures of cardiovascular risk factor control without action measures largely minimizes the quality of care provided by physicians and other healthcare providers. We suggest that assessment of quality of care can be improved by including measures of therapy intensification and physician action in the face of uncontrolled values.

Overtreatment might reflect overaggressive and potentially dangerous lowering of markers among low-risk patients, and the use of expensive condition-specific drugs with unproven mortality and/or morbidity benefits [26]. Overtreatment of cardiovascular risk factors seemed to be low in the present cohort. In a recent study, Kerr et al. found $8 \%$ of potential overtreatment for hypertension 
Table 4 Multivariable analysis of factors associated with "Appropriate Clinical Action" in response to poorly controlled hypertension, dyslipidemia, and diabetes mellitus at 12 months

\begin{tabular}{|c|c|c|c|c|c|c|c|c|}
\hline \multicolumn{3}{|c|}{$\begin{array}{l}\text { Poorly controlled hypertension } \\
\qquad(n=391)\end{array}$} & \multicolumn{3}{|c|}{$\begin{array}{l}\text { Poorly controlled dyslipidemia } \\
\qquad(n=231)\end{array}$} & \multicolumn{3}{|c|}{$\begin{array}{l}\text { Poorly controlled diabetes } \\
\text { Mellitus }(n=59)\end{array}$} \\
\hline $\begin{array}{l}\text { Proportion } \\
\text { (\%) }\end{array}$ & OR & $95 \% \mathrm{Cl}$ & $\begin{array}{l}\text { Proportion } \\
\quad(\%)\end{array}$ & OR & $95 \% \mathrm{Cl}$ & $\begin{array}{l}\text { Proportion } \\
\text { (\%) }\end{array}$ & $\mathrm{OR}$ & $95 \% \mathrm{Cl}$ \\
\hline 59.0 & & & 35.8 & & & 98.2 & & \\
\hline 66.6 & 1.38 & $(0.86-2.22)$ & 31.9 & 0.84 & $(0.41-1.71)$ & 97.9 & 0.86 & $(0.14-5.23)$ \\
\hline
\end{tabular}

$\geq 65$ years

Sex

Female

Male

Co-occurrence of other conditions

no co-occurrence of $\mathrm{HT}, \mathrm{DL}, \mathrm{DM}$

$\mathrm{HT}$ and $\mathrm{DL}$

$\mathrm{HT}$ and DM

$\mathrm{DL}$ and $\mathrm{DM}$

All 3 conditions

Number of other conditions

increase 1 co-morbidity

Risk status

No target organ disease

Target organ disease (except CAD)

CAD

Baseline level of each condition

Systolic BP

140-159 mmHg
160-179 mmHg
$\geq 180 \mathrm{mmHg}$
Diastolic BP
$90-99 \mathrm{mmHg}$
$100-109 \mathrm{mmHg}$
$\geq 110 \mathrm{mmHg}$
LDL cholesterol level
$3.4-4.1 \mathrm{mmol} / \mathrm{L}$ (130-159 mg/dL)
$4.2-4.9 \mathrm{mmol} / \mathrm{L}$ (160-189 mg/dL)
$\geq 5.0 \mathrm{mmol} / \mathrm{L}$ ( $\geq 190 \mathrm{mg} / \mathrm{dL})$
Haemoglobin A1C
8.0-8.9\%
9.0-9.9\%
$\geq 10.0 \%$

\section{9}

626

93.0

59.9

73.7

91.0
1.88

(0.87-4.08)

1.12

(0.67-1.88)

8.86

$(1.06-73.98)^{*}$

6.78

(0.71-65.14)

Hierarchical logistic regression with adjustment for all the covariates in the table. Patient factors associated with "appropriate clinical action" vs. "inappropriate clinical action" at 12 months were assessed in these multivariable models. "Appropriate clinical action" was defined as therapy modifications or return to control without therapy modification. $\mathrm{BP}=$ blood pressure; $\mathrm{CAD}=$ coronary artery disease; $\mathrm{LDL}=$ low-density lipoprotein; $\mathrm{HT}=$ hypertension; $\mathrm{DL}=$ dyslipidemia; $\mathrm{DM}=$ diabetes mellitus. OR = odds ratio; $95 \% \mathrm{Cl}=95 \%$ confidence interval; $\mathrm{NA}=$ not available. Odds Ratios are related to the first class shown for each category. Due to low number of patients with poorly controlled diabetes mellitus some calculations for proportions, odds ratios and $95 \%$ confidence interval are not feasible. Ref $=$ reference category in diabetes mellitus due to low number of patients. ${ }^{*} \mathrm{P}<0.05$ compared to reference group; ${ }^{* *} \mathrm{P}<0.01$ compared to reference group. 
among patients with diabetes mellitus with already low blood pressure $(<130 / 65 \mathrm{mmHg})$ [3]. In the present study, we extended this analysis to hypertensive patients without diabetes mellitus, and found the same rate of potential overtreatment of hypertension in the two groups (2\%). Overtreatment of hyperlipidemia has been shown to be common in the outpatient setting (8-13\%) [14,27,28].

Our study has several limitations. First, we could not identify the many potential causes of nonresponse to poor control and the reasons for intensified therapy in the face of low surrogate markers. Second, for overtreatment, widely used guidelines at the time of data collection, such as the American Diabetes Association (ADA) or Seventh Report of the Joint National Committee on Prevention, Detection, Evaluation, and Treatment of High Blood Pressure (JNC 7) [11,13] do not specify lower thresholds of blood pressure or HbA1c goals. Recent large studies have not shown significant mortality benefit among patients intensively treated for hypertension and diabetes mellitus [29-31], while one group reported increased mortality after intensive glucose lowering therapy in type 2 diabetes [32]. The ADA now mentions that less stringent treatment goals (HbA1c $>7 \%)$ may be appropriate for adults with limited life expectancy or co-morbidities [13]. The definitions of overtreatment are recent and no consensus on these new markers have been reached. To define overtreatment, we used recent publications and widely used guidelines. Third, data from the present cohort were obtained in university settings and results might differ for general practitioners in the community. Care provided by university attendings and residents might be more guideline driven, leading to increased percentage of appropriate clinical action, but also potential overtreatment. Fourth, for diabetes mellitus, our measure of physician response was not applicable to patients with insulin treatment as data on day-to-day adjustments of dosages were not reliably recorded. While we have previously shown that treatment intensification was tightly linked to improved risk factor control [4], our study did not allow conclusions on morbidity or mortality of cardiovascular risk factors with regard to quality of care including action measures. Lastly, we could not assess the predictors of each component of appropriate clinical action, because the sample size was too small for multivariate analyses.

\section{Conclusions}

In summary, evaluating whether physicians respond appropriately to poor risk factor control, in addition to proportions of patients with controlled risk factors, might provide a more clinically relevant index of quality of care. This might result in a broader view of the quality of care than relying solely on measures of proportions in control. Such measures could be more clinically relevant and acceptable to physicians than simply reporting levels of control. Overall, rates of overtreatment for cardiovascular risk factors were low, ranging from $2 \%$ to $6 \%$. Sophisticated quality measures including action measures may provide a better picture of the quality of care than relying only on measures of proportions in control.

\section{Additional file}

Additional file 1: Table S1. Diagnostic Criteria for Diabetes Mellitus, Hypertension, and Dyslipidemia; adapted from reference [5].

\section{Competing interests}

The authors declare that they have no competing interests.

\section{Authors' contributions}

SW and NR wrote the manuscript, NR designed the research, LZ, JC, EB, JMG, NR performed the research in the different Universities, SW, AG and THC performed the statistical analyses, DB, EAK and DA contributed new analytical tools. All authors' read and approved the final manuscript.

\section{Acknowledgments}

The work from SW and NR was partially supported by a grant from the Swiss National Science Foundation (SNSF 320030-138267, Principal Investigator Prof N. Rodondi). Dr T-H Collet's research is supported by a grant from the Swiss National Science Foundation (PBLAP3-145870). We would like to thank Dr Clara Podmore, MD, MPhil (MRC Epidemiology Unit, University of Cambridge, Cambridge, UK, funded by the Wellcome Trust) for editing the manuscript.

\section{Author details}

${ }^{1}$ Department of General Internal Medicine, University of Bern, Bern, Switzerland. ${ }^{2}$ Department of Clinical Research, Clinical Trials Unit, University of Bern, Bern, Switzerland. 'Department of Health Sciences and Health Policy, University of Lucerne, Lucerne, Switzerland. ${ }^{4}$ Swiss Paraplegic Research, Nottwil, Switzerland. ${ }^{5}$ Department of Ambulatory Care and Community Medicine, University of Lausanne, Lausanne, Switzerland. ${ }^{6}$ Service of Endocrinology, Diabetes, and Metabolism, Lausanne University Hospital, Lausanne, Switzerland. 'Department of Epidemiology and Biostatistics, University of California San Francisco, San Francisco, CA, USA. ${ }^{8}$ Department of Medicine, University of California San Francisco, San Francisco, CA, USA. ${ }^{9}$ Division of Internal Medicine, University Hospital of Zurich, Zurich, Switzerland. ${ }^{10}$ Medical Outpatient Department/Ambulatory Internal Medicine, University Hospital Basel, Basel, Switzerland. ${ }^{11}$ Department of Community Medicine and Primary Care, University Hospitals of Geneva and Faculty of Medicine, Geneva, Switzerland. ${ }^{12}$ Veterans Affairs Center for Clinical Management Research, HSR\&D Center of Excellence; Department of Internal Medicine, University of Michigan, Ann Arbor, MI, USA.

Received: 13 February 2014 Accepted: 27 June 2014 Published: 15 July 2014

\section{References}

1. Guthrie B, Inkster M, Fahey T: Tackling therapeutic inertia: role of treatment data in quality indicators. BMJ 2007, 335:542-544.

2. Phillips LS, Twombly JG: It's time to overcome clinical inertia. Ann Intern Med 2008, 148:783-785.

3. Kerr EA, Lucatorto MA, Holleman R, Hogan MM, Klamerus ML, Hofer TP, VA Diabetes Quality Enhancement Research Initiative (QUERI) Workgroup on Clinical Action Measures: Monitoring performance for blood pressure management among patients with diabetes mellitus: too much of a good thing? Arch Intern Med 2012, 172:938-945.

4. Selby JV, Uratsu CS, Fireman B, Schmittdiel JA, Peng T, Rodondi N, Karter AJ, Kerr EA: Treatment intensification and risk factor control: toward more clinically relevant quality measures. Med Care 2009, 47:395-402.

5. Rodondi N, Peng T, Karter AJ, Bauer DC, Vittinghoff E, Tang S, Pettitt D, Kerr EA, Selby JV: Therapy modifications in response to poorly controlled hypertension, dyslipidemia, and diabetes mellitus. Ann Intern Med 2006, 144:475-484. 
6. Kerr EA, Krein SL, Vijan S, Hofer TP, Hayward RA: Avoiding pitfalls in chronic disease quality measurement: a case for the next generation of technical quality measures. Am J Manag Care 2001, 7:1033-1043.

7. Campbell DT: Assessing the Impact of Planned Social Change. Dartmouth College, Hanover New Hampshire, USA: The Public Affairs Center; 1976.

8. Pogach L, Aron D: The Other Side of Quality Improvement in Diabetes for Seniors: A Proposal for an Overtreatment Glycemic Measure. Arch Intern Med 2012, 172:1510-1512.

9. HEDIS 2007 State of Health Care Quality. 2007 . (Accessed 1st May 2013, at http://www.ncqa.org/Portals/0/Publications/Resource\%20Library/SOHC/ SOHC_07.pdf.

10. Collet TH, Salamin S, Zimmerli L, Kerr EA, Clair C, Picard-Kossovsky M, Vittinghoff E, Battegay E, Gaspoz JM, Cornuz J, Rodondi N: The quality of primary care in a country with universal health care coverage. J Gen Intern Med 2011, 26:724-730.

11. Chobanian AV, Bakris GL, Black HR, Cushman WC, Green LA, Izzo JL Jr, Jones DW, Materson BJ, Oparil S, Wright JT Jr, Roccella EJ, the National High Blood Pressure Education Program Coordinating Committee: Seventh report of the Joint National Committee on Prevention, Detection, Evaluation, and Treatment of High Blood Pressure. Hypertension 2003, 42:1206-1252.

12. Higashi T, Wenger NS, Adams UL, Fung C, Roland M, McGlynn EA, Reeves D, Asch SM, Kerr EA, Shekelle PG: Relationship between number of medical conditions and quality of care. N Engl J Med 2007, 356:2496-2504.

13. American Diabetes Association: Standards of medical care in diabetes2011. Diabetes Care 2011, 34(Suppl 1):S11-S61.

14. Beard AJ, Hofer TP, Downs JR, Lucatorto M, Klamerus ML, Holleman R, Kerr EA, for the Diabetes Clinical Action Measures Workgroup: Assessing appropriateness of lipid management among patients with diabetes mellitus: moving from target to treatment. Circ Cardiovasc Qual Outcomes 2013, 6:66-674.

15. Uijen $A A$, van de Lisdonk EH: Multimorbidity in primary care: prevalence and trend over the last 20 years. Eur J Gen Pract 2008, 14(Suppl 1):28-32.

16. Fortin $M$, Hudon C, Haggerty J, Akker M, Almirall J: Prevalence estimates of multimorbidity: a comparative study of two sources. BMC Health Serv Res 2010, 10:111.

17. Vittinghoff E, Glidden DV, Shiboski SC, McCulloch CE: Regression methods in biostatistics: linear, logistic, survival, and repeated measures models. New York: Springer; 2005

18. Wolf-Maier K, Cooper RS, Banegas JR, Giampaoli S, Hense HW, Joffres M, Kastarinen M, Poulter N, Primatesta P, Rodríguez-Artalejo F, Stegmayr B, Thamm M, Tuomilehto J, Vanuzzo D, Vescio F: Hypertension prevalence and blood pressure levels in 6 European countries, Canada, and the United States. JAMA 2003, 289:2363-2369.

19. Asch SM, McGlynn EA, Hogan MM, Hayward RA, Shekelle P, Rubenstein L, Keesey J, Adams J, Kerr EA: Comparison of quality of care for patients in the Veterans Health Administration and patients in a national sample. Ann Intern Med 2004, 141:938-945.

20. Selby JV, Schmittdiel JA, Fireman B, Jaffe M, Ransom LJ, Dyer W, Uratsu CS, Reed ME, Kerr EA, Hsu J: Improving treatment intensification to reduce cardiovascular disease risk: a cluster randomized trial. BMC Health Serv Res 2012, 12:183.

21. Heisler M, Hogan MM, Hofer TP, Schmittdiel JA, Pladevall M, Kerr EA: When more is not better: treatment intensification among hypertensive patients with poor medication adherence. Circulation 2008, 117:2884-2892.

22. Ho PM, Magid DJ, Shetterly SM, Olson KL, Peterson PN, Masoudi FA Rumsfeld JS: Importance of therapy intensification and medication nonadherence for blood pressure control in patients with coronary disease. Arch Intern Med 2008, 168:271-276.

23. Bolen SD, Bricker E, Samuels TA, Yeh HC, Marinopoulos SS, McGuire M, Abuid M, Brancati FL: Factors associated with intensification of oral diabetes medications in primary care provider-patient dyads: a cohort study. Diabetes Care 2009, 32:25-31.

24. McEwen LN, Bilik D, Johnson SL, Halter JB, Karter AJ, Mangione CM, Subramanian U, Waitzfelder B, Crosson JC, Herman WH: Predictors and impact of intensification of antihyperglycemic therapy in type 2 diabetes: translating research into action for diabetes (TRIAD). Diabetes Care 2009, 32:971-976.

25. Willig JH, Jackson DA, Westfall AO, Allison J, Chang PW, Raper J, Saag MS, Mugavero MJ: Clinical inertia in the management of low-density lipoprotein abnormalities in an HIV clinic. Clin Infect Dis 2008, 46:1315-1318
26. Furberg CD, Berglund G, Manolio TA, Psaty BM: Overtreatment and undertreatment of hypertension. J Intern Med 1994, 235:387-397.

27. Verma A, Visintainer $P$, Elarabi M, Wartak S, Rothberg MB: Overtreatment and undertreatment of hyperlipidemia in the outpatient setting. South Med J 2012, 105:329-333.

28. Tonstad S, Rosvold EO, Furu K, Skurtveit S: Undertreatment and overtreatment with statins: the Oslo Health Study 2000-2001. J Intern Med 2004, 255:494-502.

29. Duckworth W, Abraira C, Moritz T, Reda D, Emanuele N, Reaven PD, Zieve FJ, Marks J, Davis SN, Hayward R, Warren SR, Goldman S, McCarren M, Vitek ME, Henderson WG, Huang GD, VADT Investigators: Glucose control and vascular complications in veterans with type 2 diabetes. N Engl J Med 2009, 360:129-139.

30. Patel A, MacMahon S, Chalmers J, Neal B, Billot L, Woodward M, Marre M, Cooper M, Glasziou P, Grobbee D, Hamet P, Harrap S, Heller S, Liu L, Mancia G, Mogensen CE, Pan C, Poulter N, Rodgers A, Williams B, Bompoint S, de Galan BE, Joshi R, Travert F: Intensive blood glucose control and vascular outcomes in patients with type 2 diabetes. N Engl J Med 2008, 358:2560-2572

31. McBrien K, Rabi DM, Campbell N, Barnieh L, Clement F, Hemmelgarn BR, Tonelli M, Leiter LA, Klarenbach SW, Manns BJ: Intensive and standard blood pressure targets in patients with type 2 diabetes mellitus: systematic review and meta-analysis. Arch Intern Med 2012, 172:1296-1303.

32. Gerstein HC, Miller ME, Byington RP, Goff DC Jr, Bigger JT, Buse JB, Cushman WC, Genuth S, Ismail-Beigi F, Grimm RH Jr, Probstfield JL, Simons-Morton DG, Friedewald WT, Action to Control Cardiovascular Risk in Diabetes Study Group: Effects of intensive glucose lowering in type 2 diabetes. N Engl J Med 2008, 358:2545-2559.

\section{doi:10.1186/1472-6963-14-306}

Cite this article as: Weiler et al.: Clinically relevant quality measures for risk factor control in primary care: a retrospective cohort study. BMC Health Services Research 2014 14:306.

\section{Submit your next manuscript to BioMed Central and take full advantage of:}

- Convenient online submission

- Thorough peer review

- No space constraints or color figure charges

- Immediate publication on acceptance

- Inclusion in PubMed, CAS, Scopus and Google Scholar

- Research which is freely available for redistribution 